\title{
Article
}

\section{Are you IDDSI ready?}

Boaden, Elizabeth, Lightbody, Catherine Elizabeth and Watkins, Caroline Leigh

Available at http://clok.uclan.ac.uk/25839/

Boaden, Elizabeth ORCID: 0000-0002-4647-6392, Lightbody, Catherine Elizabeth ORCID: 0000-0001-5016-3471 and Watkins, Caroline Leigh ORCID: 0000-0002-9403-3772 (2019) Are you IDDSI ready? British Journal of Neuroscience Nursing, 15 (1). ISSN 1747-0307

It is advisable to refer to the publisher's version if you intend to cite from the work. 10.12968/bjnn.2019.15.1.13

For more information about UCLan's research in this area go to http://www.uclan.ac.uk/researchgroups/ and search for <name of research Group>.

For information about Research generally at UCLan please go to http://www.uclan.ac.uk/research/

All outputs in CLoK are protected by Intellectual Property Rights law, including Copyright law. Copyright, IPR and Moral Rights for the works on this site are retained by the individual authors and/or other copyright owners. Terms and conditions for use of this material are defined in the policies page.

\section{CLoK}

Central Lancashire online Knowledge www.clok.uclan.ac.uk

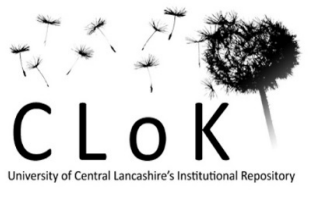




\title{
Title:
}

Are you IDDSI ready?

\section{Author details:}

Boaden E,1 Lightbody CE,1,2 Watkins, C.1,2

1 University of Central Lancashire, Preston, Lancashire, UK

2 Australian Catholic University, Sydney, Australia

\begin{abstract}
The International Dysphagia Diet Standardisation Initiative (IDDSI) global framework was launched in November 2015. It was subsequently adopted by the Royal College of Speech and Language Therapists and the British Dietetic Association following expert review and professional membership consultation. In the UK, NHS England established an External IDDSI Reference Group comprising of stakeholders including professional, catering, industry and manufacturing representatives.

The IDDSI External reference Group have endorsed a UK Aware, Prepare, Adopt model of implementation and all manufacturers and all healthcare settings are anticipated to be fully IDDSI compliant by April 2019. This requires whole system change with a comprehensive training programme. Those providing and delivering food and drink to individuals with swallowing difficulties need to familiarise themselves with food and drink consistencies and their testing methods. Resources are available to assist local healthcare institutions with implementation of the framework at www.rcslt.org / www.bda.org / www.iddsi.org.
\end{abstract}




\section{Acknowledgement}

The authors would like to acknowledge the work of the International Dysphagia Diet Standardisation Initiative committee.

\section{Conflict of interest statement}

The authors would like to declare no conflict of interests

\section{Figures}

Figure 1. International Dysphagia Diet Standardisation Initiative framework.

Figure 2. Flow Test: residue in syringe after 10 seconds equates to the fluid consistency levels within the IDDSI Framework 
Full text

Introduction

Dysphagia (swallowing difficulty) is estimated to affect 8\% (590 million) of the world's population (Cichero et al. 2017), with 5.2 million people presenting with difficulties in the UK. Swallowing is a complex neuromuscular process that involves cessation of breathing in order for food and fluid to move through the throat and into the oesophagus. As such, dysphagia is a common clinical symptom in many congenital and acquired conditions (Takizawa et al. 2016; Falsetti et al. 2009), with difficulties evident at each of the pre-oral, oral, oral transit, pharyngeal and oesophageal stages of the swallow. There is evidence that the early identification and management of individuals with swallowing difficulties, especially following stroke, plays a fundamental role in reducing the risk of malnutrition (Carrion et al. 2017), pneumonia (Bray et al. 2016; Palli et al. 2017), poor individual outcome (Turner et al. 2015; Middleton et al. 2011), mortality (Ingleman et al. 2011; Koennecke et al. 2011), and costs (Katzan et al. 2007). The health risk to individuals with swallowing difficulties is often compounded by impaired physical and cognitive function, which may impact further on the eating process. Decreased levels of alertness, fatigue, inability to maintain trunk and head alignment, reduced postural stability and tone, limb and body apraxia, visual perceptual difficulties, communication problems, a lack of insight, depression and poor oral hygiene (Boaden et al. 2017), can all affect eating, drinking and swallowing of food, fluids and medication.

There are a number of strategies that assist in the safety and efficiency of swallowing. However, some individuals with swallowing difficulties have insufficient cognition to implement the strategies throughout the day. Consequently, the modification of drink and food is a common compensatory strategy (Steele et al. 2015), which is effective in terms of reducing the risk of aspiration of food and drink into the airway (Newman et al. 2016). The main finding from a systematic review showed that there is evidence that increasing bolus viscosity with modified starch and/or xanthan gum thickeners improve the safety of swallowing in oropharyngeal dysphagia by variation in swallow physiology (Park et al. 2017; Garand et al. 2016; Jestrovic et al. 2016; Steele et al. 2015) and compensatory mechanisms (Vilardell et al. 2016). 
This reduction in the risk of aspirated material into the trachea may reduce the incidence of aspiration pneumonia, death and dependency. More recently, research has identified that not only is it important to deliver drinks that are thickened to prevent thin fluids being aspirated onto the lungs, but it is as important to ensure that drinks are not too thick. Newman and colleagues report that increasing consistency may result in post swallow residue (Newman et al. 2016) above the airway, which if not removed by clearing swallows or wash down techniques may be aspirated onto the lungs. Furthermore, the thicker the consistency, the less palatable it becomes to individuals and the incidence of noncompliance increases. It is therefore essential that the person receives the consistency prescribed. For individuals who have chewing difficulties, solid foods may also need to be modified.

UK Dysphagia Diet and Food Texture Descriptors and the International Dysphagia Diet Standardisation Initiative

Many of the prescribed foods and fluids provided to individuals with swallowing difficulties align with the UK Dysphagia Diet and Food Texture Descriptors (NPSA, RCSLT, NACC, BDA, NNNG, Hospital Catering Association 2011) and the National Descriptors for Texture Modification in Adults (BDA 2009). These frameworks were adopted by the Royal College of Speech and Language Therapists (RCSLT) and the British Dietetic Association (BDA). However, different food and fluid descriptors and frameworks continued to be used (Boaden 2011). This scenario of variation in the delivery of food and fluid consistencies is replicated between and within other primary and secondary health care settings and institutions. Non-standardisation of oral intake consistency descriptors may affect the quality of care offered to individuals with swallowing difficulties and precipitate aspiration pneumonia, a common and preventable consequence of dysphagia.

Therefore, there is a need for a framework to offer an international standardisation for consistency management. The International Dysphagia Diet Standardisation Initiative (IDDSI 2017) was launched in November 2015. It consists of a continuum of eight levels, from normal fluids to normal diet. It provides culturally sensitive colour codes and neutral terminology and definitions for texture modified 
food and fluids. It includes evidence for descriptors and testing methods for both drink thickness and food texture levels. (For full details on the framework visit webpage https://iddsi.org/Documents/IDDSIFramework-CompleteFramework.pdf)

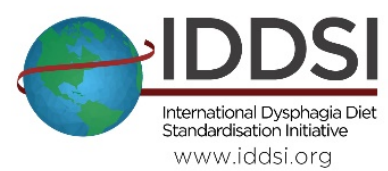

FOODS

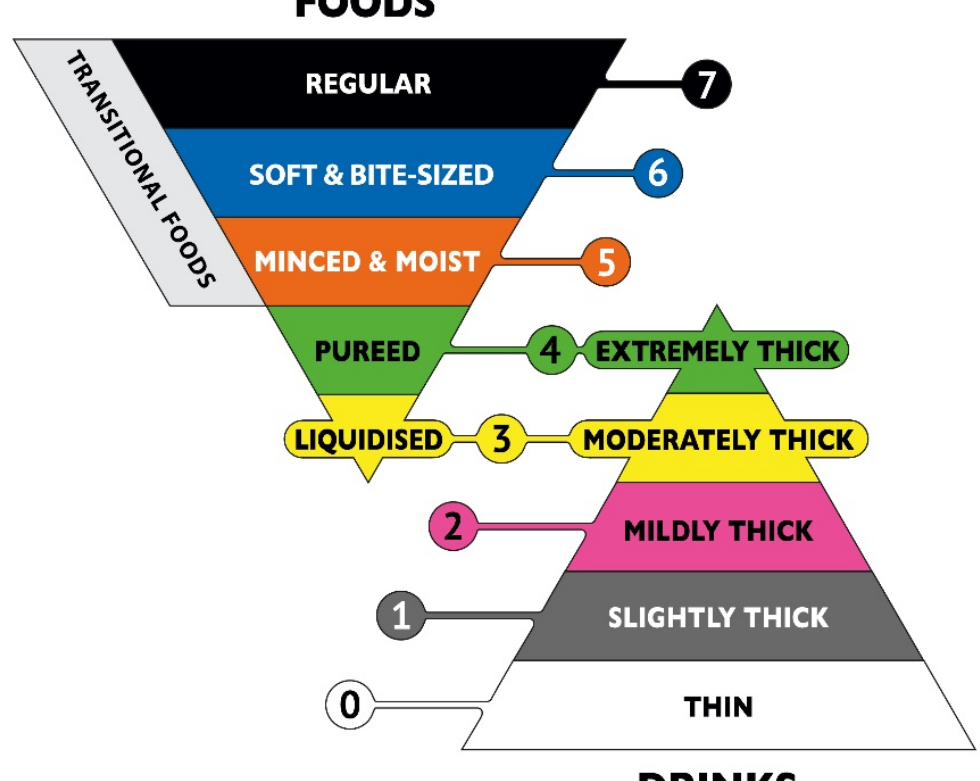

DRINKS

Figure 1. International Dysphagia Diet Standardisation Initiative framework.

Adoption

To date, adoption of the IDDSI framework globally is ongoing. In the UK, NHS England established an external IDDSI reference group comprising of stakeholders including professional, catering, industry and manufacturing representatives. Concurrently the RCSLT and the BDA have undertaken programmes of work. They independently established expert reference groups and following a recommendation from the respective professional groups and a period of consultation with their membership, these professional bodies independently and formally announced adoption the new IDDSI framework in 2017. These groups have devised a series of resources in order to facilitate 
implementation of the framework at a local level that are available from their respective websites: www.rcslt.org and www.bda.uk.com.

Roll out

There has been a published article regarding implementation of the IDDSI framework (Lam et al. 2017). However, the study was undertaken in one discrete hospital where a standardised terminology framework for fluids and food was not already utilised. In the UK, whole system change is required to deliver consistent training and accurate terminology and communication across primary and secondary care as well as educational settings, the NHS, private and voluntary facilities.

The External Reference Group have identified a UK ‘Aware, Prepare, Adopt’ model of implementation and all manufacturers and all healthcare settings are anticipated to be fully IDDSI compliant by April 2019. As part of the ‘Aware’ strategy, many organisations have issued safety alerts and established interdisciplinary strategic steering groups to oversee implementation. A timeline and plan for rollout is fundamental to the 'Prepare' strategy, with communication between healthcare staff and manufacturers of food and drink working together for successful implementation of the framework. Identified IDDSI champions and co-ordinators need to meet frequently to ensure momentum. Consideration needs to be given to training all staff e.g. community staff, GPs, pharmacists and carers within the locality who deliver modified food and fluids across all wards, care homes, educational establishments and day centres and in individual's homes.

\section{Warning}

Familiarity with and consistency of use of terminology needs to be ensured in order to avoid confusion with previous terminology and any risk to delivery of health care. More recently NHS improvement have issued a safety (NHS Improvement 2018) alert prohibiting the term 'soft' in reference to food consistency and diet. This is in response to individual healthcare staff and carer's interpretation of the term leading to incorrect diet being taken with consequential choking and death. This further enforces the need to use accurate terminology when communicating about diet and fluid modification. 
Catering departments need to revise menus and industry partners need to ensure that their products: thickening powder; supplements; modified meals; and their product information leaflets align with the NHS Improvement Safety Alert and the new IDDSI consistency framework. For many establishments who use a variety of manufacturing products, where change over to the new IDDSI framework is staggered, extra vigilance is required to ensure a successful ‘Adopt' strategy by April 2019.

Training

Healthcare staff may feel confident in the recognition of different food consistencies. However, food and drink consistencies are now determined by specific descriptors and testing methods. An overview of the food and drink descriptors and their testing methods is offered but staff must be familiar with all the details regarding the food and drink descriptors and testing methods for each consistency. Visit webpage https://iddsi.org/Documents/IDDSIFramework-CompleteFramework.pdf

Food levels 7-4 descriptors and testing methods

Staff should be aware of the introduction and classification of a new category of food consistencies termed 'transitional foods'. These products alter their consistency, typically in response to heat and/or moisture. They may therefore change from the prescribed consistency prior to delivery to the individual or within the oral cavity prior to swallowing e.g. ice cream, bread, wafers etcetera. Level 7 Regular includes all foods textures and may be various sizes. More recently, 'Easy to chew' foods have been recognised and subsumed within the Level 7 Regular for individuals who might benefit from foods that do not require a particular particle size to be identified. Level 6 Soft and Bite-Sized should be moist and tender and are required to be an appropriate size for oral processing skills i.e. $1.5 \mathrm{~cm}$ for adults and 8mm for paediatrics, to prevent solid foods being lodged in the trachea and prevent choking. Similarly, Level 5 Minced and Moist consistencies are required to have no separate thin liquid and have small lumps visible ( $4 \mathrm{~mm}$ for adults and $2 \mathrm{~mm}$ for paediatrics) that are easily squashed with the tongue. Level 4 Pureed should have no lumps and should not be sticky and should fall off a spoon when tilted. Level 3 Liquidised foods should be a smooth texture with no bits and may be drunk from a cup. 
Similarly, healthcare staff will need to be familiar with specific testing methods for food i.e. the fork pressure test and the spoon pressure tests for Level 6; the fork prong test for Level 5; the spoon tilt test for Level 5 and Level 4; and the fork drip test for Level 3.

Drink levels 4-0 descriptors and testing methods

There are new levels defined for modified drinks (Levels 4 -0). Level 4 Extremely Thick drinks cannot be drunk from a cup and may be piped or moulded. It has no lumps, is not sticky and liquid does not separate from the solid. Level 3 Moderately Thick drinks have a smooth texture, with no bits and may be drunk from a cup. Level 2 Mildly Thick will flow off a spoon, whilst Level 1 Slightly Thick drinks will flow through a straw.

The spoon tilt test may be used for Level 4 Extremely Thick and the fork drip test has been identified for use with Level 3 Moderately Thick drinks. The syringe flow test has been devised to test for levels 4-0.

The IDDSI framework uses a syringe flow test using syringes with a measured length of $61.5 \mathrm{~mm}$ from the zero to the $10 \mathrm{~mL}$ line (BDTM syringes were used for testing of the IDDSI framework, manufacturer code 301604).

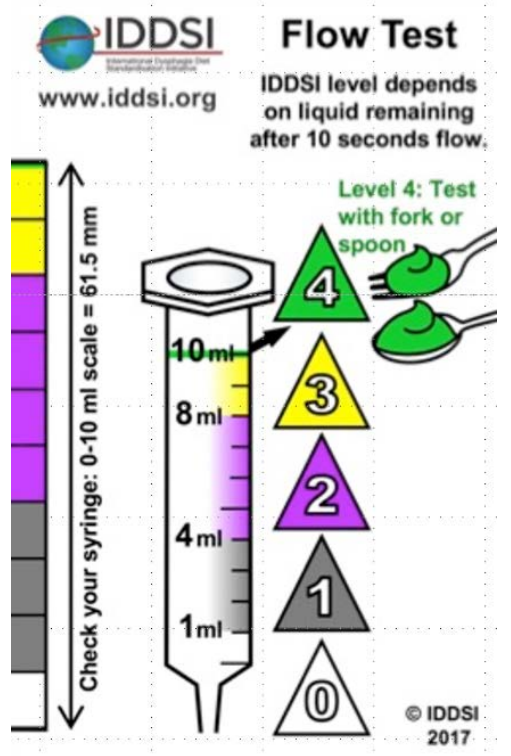


(C) The International Dysphagia Diet Standardisation Initiative 2016 @https://iddsi.org/framework/. Attribution is NOT PERMITTED for derivative works incorporating any alterations to the IDDSI Framework that extend beyond language translation. Supplementary Notice: Modification of the diagrams or descriptors within the IDDSI Framework is DISCOURAGED and NOT RECOMMENDED. Alterations to elements of the IDDSI framework may lead to confusion and errors in diet texture or drink selection for patients with dysphagia. Such errors have previously been associated with adverse events including choking and death.

Figure 2. Flow Test: residue in syringe after 10 seconds equates to the fluid consistency levels within the IDDSI Framework

The viscosity of fluid consistencies is dependent on many variables including the time taken to thicken fluids (Kim and Yoo, 2015) and the temperature of the modified drinks (Cola et al. 2012). It is therefore important that healthcare staff have a working knowledge of how to make, test and deliver individually prescribed consistencies of drinks.

The IDDSI website has literature and videos that healthcare staff can make themselves familiar with. IDDSI suggest that using the syringe flow test might be useful to use during training but do not anticipate that it will be used to test every drink given in clinical practice.

Readers are advised to engage in local plans for IDDSI implementation and familiarise themselves with resources available from the following websites; www.rcslt.org; www.bda.uk.com; www.iddsi.org.

\section{References}

Boaden E, Lyons M, Singhrao SK, Dickinson H, Leathley M, Lightbody CE, McLoughlin A, Khan Z, Crean S, Smith C, Higham S, Watkins C. 2017. Oral flora in acute stroke patients: A prospective exploratory observational study. Gerodontology. 34(3):343-356. doi: 10.1111/ger.12271. Epub 2017 May 22.

Boaden EE. 2011. Improving the identification and management of aspiration after stroke. $\mathrm{PhD}$, University of Central Lancashire, Preston, Lancashire, UK.

Bray BD, Smith CJ, Cloud GC, Enderby P, James M, Paley L, Tyrrell PJ, Wolfe CD, Rudd AG, SSNAP Collaboration. 2016. The association between delays in screening for and assessing dysphagia after acute stroke, and the risk of stroke-associated pneumonia. Journal of Neurology, Neurosurgery, and Psychiatry. 88(1), 25- 30. doi: 10.1136/jnnp-2016-313356. Epub 2016 Jun 13.

British Dietetic Association. 2009. The National Descriptors for Texture Modification in Adults [internet]. Available from http://www.acquiredbraininjury-education.scot.nhs.uk/wpcontent/uploads/sites/11/National-Descriptors-Texture-Modification-Adults-2009.pdf

Carrion S, Roca M, Costa A, Arreola V, Ortega O, Palomera E, Serra-Prat M, Cabré M, Clavé P. 2017. Nutritional status of older patients with oropharyngeal dysphagia in a chronic versus an acute clinical situation. Clinical Nutrition. 36 (4): 1110-6. doi: 10.1016/j.clnu.2016.07.009.

Cichero JA, Lam P, Steele C, Hanson B, Chen J, Dantas RO, Duivestein J, Kayashita J, Lecko C, Murray J, Pillay M, Riquelme L, Stanschus S. 2017. Development of international terminology and 
definitions for texture-modified foods and thickened fluids used in dysphagia management: the IDDSI framework. Dysphagia. 32(2),293-314.

Cola PC, Gatto AR, da Silva RG, Spadotto AA, Ribeiro PW, Schelp AO, Carvalho LR, Henry MACA. 2012. Taste and temperature in swallowing transit time after stroke. Cerebrovascular Diseases Extra. 2(1):45-51. doi:10.1159/000339888.

Falsetti P, Acciai C, Palilla R, Bosi M, Carpinteri F, Zingarelli A, Pedace C, Lenzi L. 2009. Oropharyngeal dysphagia after stroke: incidence, diagnosis, and clinical predictors in patients admitted to a neurorehabilitation unit. Journal of Stroke and Cerebrovascular Diseases. 18(5):329-35. doi: 10.1016/j.jstrokecerebrovasdis.2009.01.009.

Garand KL, Kent A, Hill EG, Julie B, Pearson WG, Bonnie MH. 2016. Quantifying oropharyngeal swallowing impairment in response to bolus viscosity. Dysphagia. 31(6):819.

Ingeman A, Andersen G, Hundborg HH, Svendsen ML, Johnsen SP. 2011. In-hospital medical complications, length of stay, and mortality among stroke unit patients. Stroke. 42, 3214- 8.

International Dysphagia Diet Standardisation Initiative. 2017. Complete IDDSI Framework Detailed definitions. [internet]. Available from http://iddsi.org/framework/

Jestrovic I, Coyle JL, Perera S, Sejdic E. 2016. Functional connectivity patterns of normal human swallowing: difference among various viscosity swallows in normal and chin-tuck head positions. Brain Research. 1652((Coyle) Department of Otolaryngology, School of Medicine, University of Pittsburgh, Pittsburgh, PA, United States):158-169

Katzan IL, Sawson NV, Thomas CL, Votruba ME, Cebul RD. 2007. The cost of pneumonia after acute stroke. Neurology. 68(22), 1938- 43. doi:10.1212/01.wnl.0000263187.08969.45

Kim S, Yoo B. 2015. Viscosity of dysphagia oriented cold thickened beverages: effect of setting time at refrigeration temperature. IJLCD. 50(3)397-402. doi.org/10.1111/1460-6984.12141.

Koennecke HC, Belz W, Berfelde D, Endres M, Fitzek S, Hamilton F, Kreitsch P, Mackbert BM, Nabavi DG, Nolte CH, Pöhls W, Schmehl I, Schmitz B, von Brevern M, Walter G, Heuschmann PU, Berlin Stroke Register Investigators. 2011. Factors influencing in-hospital mortality and morbidity in patients treated on a stroke unit. Neurology. 77, 965- 72.

Lam P, Stanschus S, Zaman R, Cichero JAY. 2017. The International Dysphagia Diet Standardisation Initiative (IDDSI) framework: the Kempen pilot. BJNN/Stroke Association supplement. 13(2), 2017: S18-S26.

Middleton S, McElduff P, Ward J, Grimshaw JM, Dale S, D’Este C, Drury P, Griffiths R, Cheung NW, Quinn C, Evans M, Cadilhac D, Levi C, QASC Trialists Group. 2011. Implementation of evidence-based treatment protocols to manage fever, hyperglycaemia, and swallowing dysfunction in acute stroke (QASC): a cluster randomised controlled trial. Lancet. 378(9804), 1699- 706. doi: 10.1016/S0140-6736(11)61485-2. Epub 2011 Oct 11.

National Patient Safety Agency, Royal College of Speech and Language Therapists, National Association of Care Catering, British Dietetic Association, National Nurses Nutrition Group, Hospital Caterers Association. 2011. Dysphagia Diet Food Texture Descriptors [internet]. Available from http://www.hospitalcaterers.org/media/1160/dysphagia-descriptors.pdf

Newman R, Vilardell N, Clavé P, Speyer R. 2016. Effect of bolus viscosity on the safety and efficacy of swallowing and the kinematics of the swallow response in patients with oropharyngeal dysphagia: white paper by the European Society for Swallowing Disorders (ESSD). Dysphagia. 31: 232-249. doi. 10.1007/s00455-016-9696-8

NHS Improvement. 2018. Improvement.nhs.uk/resources/patient-safety-alerts Alert reference number: NHS/PSA/RE/2018/004 Resource Alert. [internet]. Available from 
https://improvement.nhs.uk/documents/2955/Patient_Safety_Alert_-

_Resources_to_support_safer_modification_of_food_and_drink_v2.pdf

Palli C, Fandler S, Doppelhofer K, Niederkorn K, Enzinger C, Vetta C, Trampusch E, Schmidt R, Fazekas F, Gattringer T. 2017. Early dysphagia screening by trained nurses reduces pneumonia rate in stroke patients. A clinical intervention study. Stroke. 48(9), 2583- 5. doi:

10.1161/STROKEAHA.117.018157. Epub 2017 Jul 17.

Park D, Shin CM, Ryu JS. 2017. Effect of different viscosities on pharyngeal pressure during swallowing: a study using high-resolution manometry. Archives of Physical Medicine and Rehabilitation. 98(3):487-4942.

Steele CM, Alsanei WA, Ayanikalath S, Barbon CEA, Chen J, Cichero JAY, Coutts K, Dantas RO, Duivestein J, Giosa L, Hanson B, Lam P, Lecko C, Leigh C, Nagy A, Namasivayam AM, Nascimento WV, Odendaal I, Smith CH, Wang H. 2015. The influence of food texture and liquid consistency modification on swallowing physiology and function: a systematic review. Dysphagia. 30(1):2-26. http://doi.org/10.1007/s00455-014-9578-x

Takizawa C, Gemmell E, Kensworthy J, Speyer R. 2016. A systematic review of the prevalence of oropharyngeal dysphagia in stroke, Parkinson's disease, Alzheimer's disease, head injury and pneumonia. Dysphagia. 31(3):434-41. doi: 10.1007/s00455-016-9695-9. Epub 2016 Mar 12.

Turner M, Barber M, Dodds H, Murphy D, Dennis M, Langhorne P, Macleod MJ. 2015. Scottish Stroke Care Audit. Implementing a simple care bundle is associated with improved outcomes in a national cohort of patients with ischemic stroke. Stroke. 46(4), 1065- 70. doi:

10.1161/STROKEAHA.114.007608. Epub 2015 Feb 12.

Vilardell N, Rofes L, Arreola V, Speyer R, Clave P. 2016. A comparative study between modified starch and xanthan gum thickeners in post-stroke oropharyngeal dysphagia. Dysphagia. 31(2):169179. doi: 10.1007/s00455-015-9672-8. Epub 2015 Nov 25.

Key points: You must supply 4-6 full sentences that adequately summarise the major themes of your article.

The International Dysphagia Diet Standardisation Initiative (IDDSI) framework has been adopted by the Royal College of Speech and Language Therapists and the British Dietetic Association.

Catering, industry and manufacturers of food and fluid consistencies that provide services to individuals with swallowing difficulties need to be compliant with the new framework and change instructions for use by April 2019.

All healthcare and educational institutions will be required to implement the framework by April 2019.

All healthcare staff need to make themselves aware and understand the IDDSI framework to ensure they deliver the correct consistency and therefore eliminate the risk to individuals who have swallowing difficulties in the transition period to the IDDSI framework.

Resources are available to assist local healthcare institutions with implementation of the framework at www.rcslt.org / www.bda.org / www.iddsi.org.

Reflective questions: Please supply 3-5 questions based on your article that readers can use for reflective notes or discussion, which may be used to count towards their NMC revalidation. These should be open-ended questions.

Why is there a need to implement a new diet and fluid framework? 
How can you ensure that you are familiar with all food, fluid and medications in a format that reflects the IDDSI framework?

What teams within your organisation would you access or engage with in order to be able to deliver all food, fluid and medications in a format that reflects the IDDSI framework? 